\title{
Bulk Fill Resin Composite Materials Cured with Single-Peak versus Dual-Peak LED LCUs
}

\author{
Aldossary Mohammed ${ }^{1,2}$, Roebuck Elizabeth $M^{1}$, Santini Ario ${ }^{3^{\star}}$ \\ 1 Department of Paediatric Dentistry. The University of Edinburgh, Edinburgh Dental Institute, Lauriston Place, Edinburgh EH3 9HA, United Kingdom \\ 2 King Salman Hospital, Ministry of Health, Riyadh, Kingdom of Saudi Arabia \\ 3 The University of Medicine \& Pharmacy, Tg-Mures, Romania
}

\begin{abstract}
Introduction: Manufactures claim that recently introduced bulk fill materials (BFM) can be cured adequately in 4 mm increments. This requires adequate light energy to be transmitted through the material to ensure adequate polymerization at the bottom of the increment.

Aim: To compare the total light energy transmission through three BFMs and

bottom/top (B/T) surface Vickers hardness $(\mathrm{VH})$ when cured with single-peak versus dual-peak LED LCUs.

Methods and Materials: Samples $(n=5)$ of two viscous BFMs, Tetric EvoCeram ${ }^{\circledR}$ Bulk Fill X-tra fil ${ }^{\circledR}[X F]$ flowable SureFil, were prepared. A conventional RBC, Tetric EvoCeram ${ }^{\circledR}$ was used as a control. Using MARC ${ }^{\circledR}$ RC, the irradiance delivered to top surface of samples was adjusted to $1200 \mathrm{~mW} / \mathrm{cm}^{2}$. Samples were cured with singlepeak EliparTM S10 or dual-peakBluephase ${ }^{\circledR}$ G2 for 10 seconds and irradiance transmitted to the bottom surface measured. Samples were stored for 24 hours, prior to $\mathrm{VH}$ measurements $\mathrm{B} / \mathrm{T} \mathrm{VH}$ ratios were calculated. Statistically analysed used oneway ANOVA ( $\alpha=0.05)$.

Results: There was no statistically significant difference for $\mathrm{B} / \mathrm{T}$ total energy

transmission between materials except XF with EliparTM S10 $(P<0.001)$. Total energy transmission ranged from $0.7 \mathrm{~J} / \mathrm{cm} 2 \mathrm{lo} 1.5 \mathrm{~J} / \mathrm{cm} 2$. There was no statistically significant difference for $\mathrm{B} / \mathrm{T} \mathrm{VH}$ ratios between materials $(\mathrm{P}>0.05)$ when materials were cured with single-peak versus dual-peak LCU's, XF>SDR>TEC>TBF. TBF alone, did not reach the generally accepted B/T VH of $80 \%$.

Conclusions: Both single-peak and dual-peak LCU's were equally effective for curing the studied bulk fill materials. Manufacture's recommended total energy delivered to the top surface may not always be sufficient for effective curing.
\end{abstract}

Keywords: Bulk-Fill Composite, Single-peak LED, Dual-peak LED

Received: 23 September 2015 / Accepted: 08 January 2016

\section{Introduction}

Resin-Based Composite (RBC) is widely used in Dentistry to restore anterior and posterior teeth. There have been many advances in RBCs development to improve their clinical success rate and overcome the many disadvantages of the first materials [1]. These materials cure with visible light, and the light curing units have also undergone development to match the need of composite materials [2]. Recently, bulk fill composite materials were introduced to be placed in the cavity in bulk, claiming replacement of the traditional layering technique.

Resin-Based Composites became available to Dentistry in the 1960's following the development of the first methacrylate-based polymer system by Bowen in 1962 [3].

The early RBCs were, in the main, used in the anterior region, where the colour of amalgam was not desired. At that time, all materials were chemically cured. With the advent of photo-polymerization, Ultra-violet (UV) light curing systems superseded these and, in the late 1970's, the first report about a dental filling material that was cured with blue light in the visible range was published [4]. Effective dentine bonding agents became available at the beginning of the 1990's, and since then, composites have found increasingly broad use as a universal restora-

* Correspondence to: Ario Santini

E-mail: ariosantini@hotmail.com tive material [5]. Furthermore, there has been a growing demand for aesthetic restorations, not only in the anterior region, but increasingly also in posterior teeth. This, in turn, has resulted in the quest for composite materials that offer improved physical, aesthetic, and handling properties. The advent of bleaching has also resulted in the need for whiter shades of RBCs [6].

The total energy $\left(\mathrm{J} / \mathrm{cm}^{2}\right)$ is the result of irradiance intensity $\left(\mathrm{mW} / \mathrm{cm}^{2}\right)$ and exposure time (second). There is almost full agreement in the literature about the total energy concept which states that the result of multiplying intensity by curing time should always result in the same total energy, thus increasing intensity and reducing time, or decreasing intensity and increasing time can result in the same total energy delivered to the restoration surface. However, there is some question about the validity of reciprocity for combinations of irradiance and time particularly high irradiance and short time [7-9].

The total energy required to achieve sufficient polymerization is widely controversial in the literature and recent findings of literature are summarised in Table I.

When the cavity is large, incremental placement of 2 $\mathrm{mm}$ thickness composite was recommended to reduce the polymerization shrinkage stress [10] and to avoid the reduction in light transmission through the material to the bottom surface $[11,12]$. This was used as the gold standard [13-15]. 
Table I. Recommended total energy required for sufficient curing in the literature

\begin{tabular}{lcc}
\hline Author & $\begin{array}{c}\text { Total energy } \\
\text { recommended }\end{array}$ & Thickness of material \\
\hline Lee and Greene, 1994 & $>12 \mathrm{~J} / \mathrm{cm}^{2}$ & $2 \mathrm{~mm}$ \\
Rueggeberg et al. 1994 & $21-24 \mathrm{~J} / \mathrm{cm}^{2}$ & $2 \mathrm{~mm}$ \\
Sobrinho et al. 2000 & $21-24 \mathrm{~J} / \mathrm{cm}^{2}$ & $2 \mathrm{~mm}$ \\
Yap and Seneviratne, 2001 & $>12 \mathrm{~J} / \mathrm{cm}^{2}$ & $2 \mathrm{~mm}$ \\
Yoon et al., 2002 & $8-16 \mathrm{~J}^{2} \mathrm{~cm}^{2}$ & $2 \mathrm{~mm}$ \\
Fan et al. 2002 & $16 \mathrm{~J} / \mathrm{cm}^{2}$ & $>3 \mathrm{~mm}$ \\
& $6-12 \mathrm{~J} / \mathrm{cm}^{2}$ up to & $1.5 \mathrm{~mm}$ \\
Emami and Soderholm, 2003 & $18 \mathrm{~J} / \mathrm{cm}^{2}$ & $2 \mathrm{~mm}$ \\
Da Silva et al., 2008 & $>5-15 \mathrm{~J} / \mathrm{cm}^{2}$ & $4-6 \mathrm{~mm}$ \\
Calheiros et al,. 2008 & $>30 \mathrm{~J} / \mathrm{cm}^{2}$ & $2 \mathrm{~mm}$ \\
Howard et al. 2010 & $>17 \mathrm{~J} / \mathrm{cm}^{2}$ & $2 \mathrm{~mm}$ \\
\hline
\end{tabular}

However, curing a RBC incrementally carries the risk that voids and/or contamination may be incorporated between the layers. Bond failure between increments has also been reported and the technique can be time consuming, thus increasing the potential for further contamination [16].

More recently, in an attempt to overcome some of the disadvantages of $2 \mathrm{~mm}$ incremental packing, bulk fill materials (BFMs) have been introduced to the market claiming that they would allow a $4 \mathrm{~mm}$ bulk placement in one layer while allowing sufficient polymerization.

Two types of BFMs are available in the market, viscous and flowable. The flowable BFMs have been recommended for use in low load bearing areas and was aimed to place in one layer of $4 \mathrm{~mm}$ thickness to reduce polymerization stress being mandatory covered by a $2 \mathrm{~mm}$ layer of conventional RBC, $[17,18]$ because the modulus elasticity and hardness were reduced [19]. The manufacturers of these materials stated some changes in composition in order to achieve the adequacy of bulk curing. It seems that manufacturers have followed different strategies to achieve this.

Ivoclar Vivadent introduced Tetric EvoCeram Bulk Fill as a viscous composite produced mainly for use in posterior teeth. They claimed two reasons why $4 \mathrm{~mm}$ increments could to be cured sufficiently. Firstly, by using two types of fillers with different mean particle sizes in order to match the refractive index of fillers to that of the monomer matrix for the ease of light transmission. Secondly, by using a patented photo-initiator (Ivocerin ), in addition to the standard systems, as a booster to make the polymerization faster and reliable in 10 seconds of curing by a dual-peak LED LCU. In addition, they claimed the use of special shrinkage stress relievers to reduce the polymerization shrinkage. Some manufacturers reduced the filler volume and increased the filler size, such as in $\mathrm{X}$-tra base, X-tra fil and SureFil SDR ${ }^{{ }^{\top} M}$. Consequently, the specific surface between fillers and organic matrix was lowered, thus reducing light scattering.

One example of the flowable materials is Smart dentin replacement/ Shrinkage decreased resin (SDR) or $\mathrm{SDR}^{\mathrm{TM}}$ technology with modification to monomer (high weight modulator embedded in the centre of monomer) to be less shrinkage.

Because of the decrease in the intensity of the light transmitting through the material the main concern with these BFMs is to ensure sufficient polymerization at the deeper portions and the bottom by receiving enough light energy. Also, concerns regarding increased stress and deformation as a result of curing in large increments.

The potential disadvantages of BFMs can include possibility of more voids as placed in the mass of material, difficulty of making adequate contact areas, more stress as the entire mass polymerize at one time, and inadequate curing in the deepest part of the material [20].

In the literature, there are few studies evaluating some of the properties of the BFMs such as polymerization shrinkage, hardness, microleakage, marginal integrity, and creep deformation [21,22].

A recent in vitro study by [23] used two BFMs, Tetric EvoCeram Bulk Fill and X-tra base, to investigate the effect of curing time and light tip distance using a single peak LCU, and measured the light transmission by MARC and degree of conversion (DC) using FTIR. They concluded the validity of curing BFMs in $4 \mathrm{~mm}$ thick increments.

In an in vitro study, [24] X-tra fil (VOCO) was investigated when placed in bulk and incrementally and cured with two LED LCUs. They found no difference in Vickers Hardness between the two techniques. However, in their study, it was apparent the use of high total energy delivered to the top surface ranged from $24 \mathrm{~J} / \mathrm{cm}^{2}$ to $52 \mathrm{~J} / \mathrm{cm}^{2}$ in addition to the limited thickness of samples to $3.5 \mathrm{~mm}$.

In an in vitro study, [25] the mechanical properties, $\mathrm{VH}$ and DC of SureFil SDR ${ }^{\mathrm{TM}}$ and another flowable composites, were compared when cured for 10, 20 and $40 \mathrm{sec}-$ onds respectively. Variation between the materials with different curing parameters were shown to be statistically different. However, the authors recommended that $4 \mathrm{~mm}$ bulk specimens be cured for 20 seconds when total energy of $24 \mathrm{~J} / \mathrm{cm}^{2}$ was delivered to the top surface, which was higher than the manufacturers' recommendations.

Another study [26] used five BFMs including Tetric EvoCeram Bulk Fill and X-tra base. Elipar ${ }^{\mathrm{TM}} \mathrm{S} 10$ $\left(1200 \mathrm{~mW} / \mathrm{cm}^{2} \times 20 \mathrm{sec}\right)$ delivering $24 \mathrm{~J} / \mathrm{cm}^{2}$ was used and this is higher than what recommended by the manufacturers. In agreement with the manufacturer claims, it was concluded that the materials could be cured to an acceptable depth with increments ranging from 4 to $5 \mathrm{~mm}$.

Another recent study by [27] investigated the light transmission and micromechanical properties of seven BFMs (three viscous and four flowable) using MARC compared to seven conventional composites (five viscous and two flowable). It was found that most of the BFMs tested were more translucent and the flowable BFMs showed the lowest mechanical properties including $\mathrm{VH}$.

Alshali et al. [28] used eight materials, four flowable bulk and four flowable conventional, including SDR and 
X-tra base and investigating the DC using FTIR after curing directly or after 24 hours. Although their BFMs' results were comparable to the conventional materials, there was variation between materials. A major criticism is that a QTH LCU was used which delivered only $12 \mathrm{~J} /$ $\mathrm{cm}^{2}$ which was less than the manufacturer' recommendation for some of the materials tested.

It was apparent that most of these studies were not following manufacturers recommendations regarding the least recommended total energy required. In addition, a variation in protocol, LCUs and techniques were used.

Many factors affect the adequate polymerization of RBCs. Some of these factors are related to the materials themselves, for example, light transmission, material composition, shade, opacity and material thickness. Other factors depend on the LCU type, irradiance, curing time and the tip-to-material surface distance.

The new BFMs were introduced recently to overcome the disadvantages of the traditional $2 \mathrm{~mm}$ layering technique saving clinical time when restoring larger cavity preparations and thus reducing the potential for contamination.

There is little evidence indicating that sufficient polymerization takes place in the new BFMs when used in $4 \mathrm{~mm}$ bulk placement in one layer. Also, previous workers had not investigated the effect of different types of LCUs on the polymerization and did not match the delivered top total energy to the recommended total energy required by the manufacturers.

Manufactures claim that recently introduced bulk fill materials can be cured adequately in $4 \mathrm{~mm}$ increments. This requires adequate light energy to be transmitted through the material to ensure adequate polymerization at the bottom of the increment.

The aim of the present study is to compare the total light energy transmission through three BFMs and bottom/top (B/T) surface Vickers hardness $(\mathrm{VH})$ when cured with single-peak versus dual-peak LED LCUs.

\section{Null Hypotheses}

1. There was no difference in the light energy transmitted through BFMs when cured with a single peak or a dual peak LED LCU.

2. There was no difference in the bottom to top surface microhardness ratio of BFMs when cured with a single peak or a dual peak LED LCU.

\section{Methods \& Materials}

The materials used in the study are given in Table II.

Samples $(\mathrm{n}=5)$ of two viscous BFMs, Tetric EvoCeram Bulk Fill [TBF], (Ivoclar Vivadent), X-tra fil ${ }^{\circ}$ [XF], (Voco), and one flowable BFM, SureFil SDR ${ }^{\mathrm{TM}}$ [SDR], (Dentsply), were prepared in $4 \mathrm{~mm}$ deep Delrin rings (DuPont, Mississauga, Ontario, Canada). A conventional RBC, Tetric EvoCeram [TEC], (Ivoclar Vivadent) was used as a control. Using MARC $^{\circ} \mathrm{RC}$, the irradiance delivered to the top surface of the samples was adjusted to $1200 \mathrm{~mW} /$ $\mathrm{cm}^{2}$. Samples were then cured with single-peak Elipar ${ }^{\mathrm{TM}}$ S10 (3M ESPE) or dual-peak; Bluephase G2 (Ivoclar Vivadent) LED LCU's for 10 seconds and the irradiance transmitted to the bottom surface measured. Additionally, MARC $^{\circ}$ internal soft-ware calculated the total energy in all cases. Samples were stored post-irradiation in a dry, sealed, light-proof container at room temperature $(21+/-$ $1^{\circ} \mathrm{C}$ ) for 24 hours, prior to taking VH measurements (X3) from the top and bottom surfaces of each sample using a micro-hardness machine (HM-200 Series, Mitutoyo Corporation, Tokyo, Japan) with an applied $200 \mathrm{~g}$ load for 10 seconds. B/T VH ratios were calculated. Data were statistically analysed using one-way ANOVA $(\alpha=0.05)$.

The following LCUs were used.

1. Single Peak LCU: EliparTM S10, 3M ESPE, Spectral output (wavelength) 430-480 nm, Light Intensity $1200 \mathrm{~mW}-10 \% /+20 \%$, Tip $10 \mathrm{~mm}$

2. Dual Peak LCU: Bluephase G2, Ivoclar Vivadent AG, Schaan, Liechtenstein, Spectral output (wavelength) 380-515 nm Second peak at approx. $410 \mathrm{~nm}$, Light Intensity $1200 \mathrm{~mW} / \mathrm{cm}^{2}+/-10 \%$ (high power mode), Tip $10 \mathrm{~mm}$

Table II. RBCs used in this study

\begin{tabular}{|c|c|c|c|}
\hline Material & Organic Matrix & Photoinitiators & Filler \\
\hline \multicolumn{4}{|c|}{ Viscous Bulk-fill materials } \\
\hline $\begin{array}{l}\text { Tetric EvoCeram® } \\
\text { BulkFill }\end{array}$ & Dimethacrylate & $\begin{array}{l}\text { CQ TPO } \\
\text { Patented light activator; } \\
\text { Ivocerin } \AA\end{array}$ & $\begin{array}{l}\text { Barium aluminium silicate glass Ytterbium trifluoride } \\
\text { (YbF3) Mixed oxide and Prepolymers. } \\
80 \% \text { by weight } \\
60 \% \text { by volume }\end{array}$ \\
\hline X-tra fil $\circledast$ & Bis-GMA UDMA TEGDMA & Not specified & $\begin{array}{l}\text { Inorganic fillers (not specified) } \\
86 \% \text { by weight } \\
70 \% \text { by volume }\end{array}$ \\
\hline \multicolumn{4}{|c|}{ Flowable Bulk-fill materials } \\
\hline SureFil SDRTM & Modified UDMA, EBPADMA TEGDMA & $\mathrm{CQ}$ & $\begin{array}{l}\text { Ba-Al-F-B silicate glass, Sr-Al- F silicate glass } \\
68 \% \text { by weight } \\
44 \% \text { by volume }\end{array}$ \\
\hline \multicolumn{4}{|c|}{ Viscous Conventional materials } \\
\hline Tetric EvoCeram $®$ & $\begin{array}{l}\text { Bis-GMA } \\
\text { UDMA } \\
\text { Bis-EMA }\end{array}$ & Not specified & $\begin{array}{l}\text { Barium glass } \\
\text { Ytterbium trifluoride (YbF3), Mixed oxide and Pre- } \\
\text { polymers. } \\
82.5 \% \text { by weight }\end{array}$ \\
\hline
\end{tabular}




\section{Measuring Instruments}

The MARC ${ }^{\ominus}$-Resin Calibrator (MARC ${ }^{\oplus}$-RC), (BlueLight Analytics Inc., Halifax, Nova Scotia, Canada) was used to measure light energy data (Figure 1).

Micro Vickers Hardness Testing Machine (HM-200 Series, Mitutoyo Corporation, Tokyo, Japan) used to record Vickers hardness data from the top and bottom surfaces of the cured specimens (Figure 2).

The temperature and humidity of the room were recorded every hour using the Diplex ${ }^{\odot}$ thermometer. (Diplex ${ }^{\oplus}$ thermometer, London, UK)

\section{Calibration and Standardisation of the LCU Intensity}

Care was taken to be away from the direct light of the ceiling lights and the laptop screen to reduce any possible external effect on the MARC ${ }^{\otimes}$-RC sensors throughout the experimental phase.

Prior to LCU calibration, a clear Mylar strip was placed over the top sensor and held in place with clear adhesive tape $\left(\right.$ Sellotape ${ }^{\circledast}$ ), placed at both ends of the strip and away from the top sensor.

The EliparTM S10 LCU was powered cordless with full charge, while the Bluephase ${ }^{\circledast}$ G2 was powered directly from the mains supply.

The EliparTM S10 was mounted on the MARC ${ }^{\oplus}-\mathrm{RC}$ fixing arm, fixed and centred perpendicularly over the top sensor. The Elipar ${ }^{\mathrm{TM}}$ S10 was activated, and moved up and down using the vertical adjustment, to reach irradiance (intensity) of $1200 \mathrm{~mW} / \mathrm{cm}^{2}$. The irradiance was shown in real-time on the laptop screen. The Elipar ${ }^{\mathrm{TM}}$ S10 calibration was reconfirmed by irradiating the top sensor of MARC ${ }^{\otimes}$-RC and then positioned in the same horizontal plane by horizontal adjustment over the bottom sensor before sample preparation.

After curing all samples of the Elipar ${ }^{\mathrm{TM}}$ S10, the same procedure of calibration was repeated for the Bluephase ${ }^{\circledast} \mathrm{G} 2$.

\section{Sample Preparation and Measurement of Bottom Light Energy and Light Transmission}

For all combinations of BFM (3), LCU (2) and total top energy of $12 \mathrm{~J} / \mathrm{cm}^{2}$, five $4 \mathrm{~mm}$ thick samples were prepared. This gave six groups with a total of thirty samples.

In order to compare the BFMs used in this study to the conventional composite Tetric EvoCeram ${ }^{\circledast}$, as a control, a conventional composite from one of the manufacturers (Ivoclar Vivadent) of the BFMs (Tetric EvoCeram ${ }^{\circledast}$ Bulk Fill) was used. It was placed in $2 \mathrm{~mm}$ thick increment, and the rest of the methodology was the same using the combination of TetricEvoCeram ${ }^{\oplus}(1)$, LCU (2) and total top energy of $12 \mathrm{~J} / \mathrm{cm}^{2}$. This gave extra 2 control groups with a total of ten samples. This gave a total of 8 groups with a total of 40 samples.

The Delrin ${ }^{\circledR}$ ring was placed on a clear Mylar strip on the glass slab. In the case of the flowable BFMs, the material was injected directly in the ring placed over the bottom sensor of MARC ${ }^{\circledR}$ RC with Mylar strip in place.

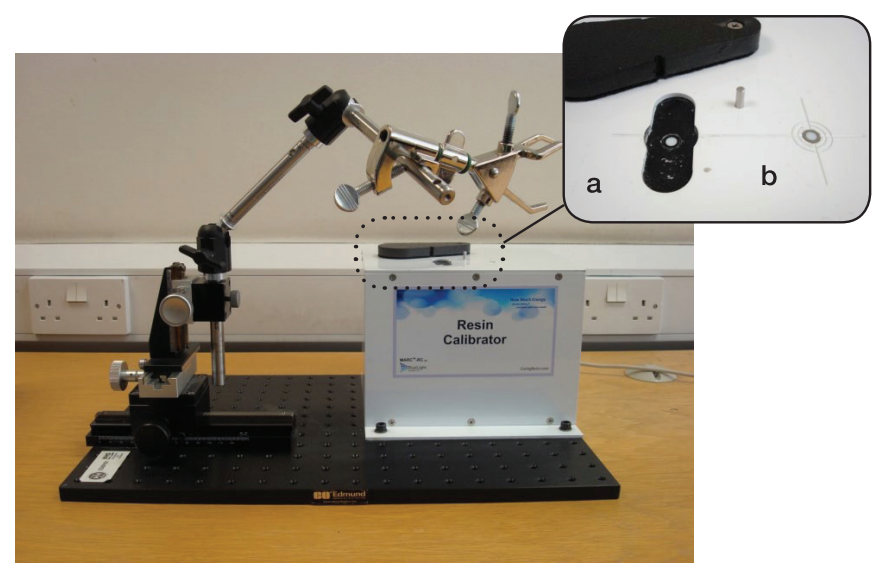

Fig. 1. MARC ${ }^{\circledR}-\mathrm{RC}$ and arrangement of the sensors (inset) (a) bottom surface sensor, and (b) top surface sensor

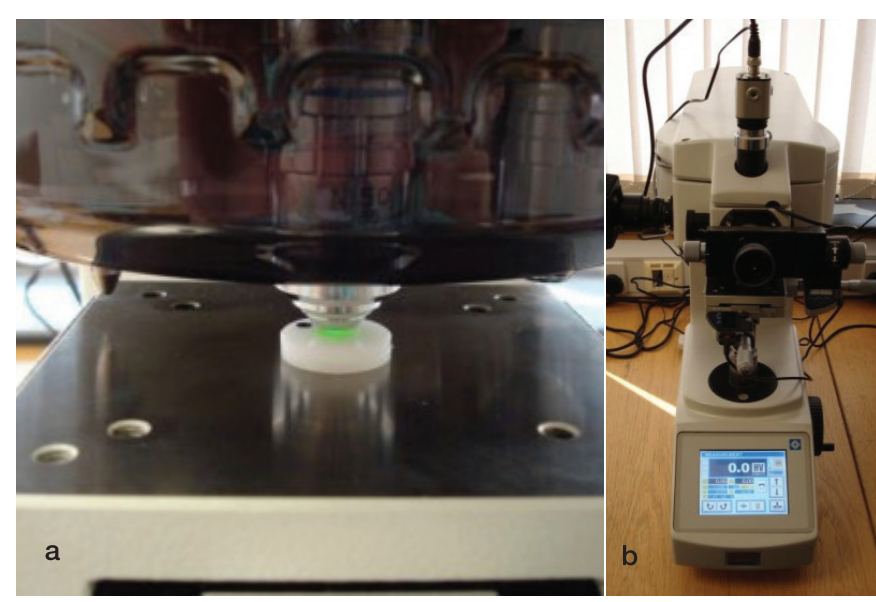

Fig. 2. Micro Vickers Hardness Testing Machine: (a) The VH tester; (b) Microscope over a sample on testing platform

The samples were prepared by placing a single increment of X-tra fil $^{\oplus}$ viscous BFM in the lumen of the $4 \mathrm{~mm}$ thick Delrin ${ }^{\circledR}$ ring, using a clean and dry flat plastic instrument. The material was packed, flattened and excess material removed with the flat plastic instrument. Each sample was covered by another clear Mylar strip, and pressed by manual finger load to extrude excess material and create a flat surface. Once prepared, the Delrin ${ }^{\circledR}$ ring with the sample of RBC was placed over the bottom sensor.

The Elipar ${ }^{\mathrm{TM}}$ S10 was activated for $10 \mathrm{sec}$ and the total light energy reaching the bottom surface of the sample, was recorded by the sensor. The data were shown on the laptop screen and saved on the computer related to the bottom surface. In this way, a known total light energy of $12 \mathrm{~J} / \mathrm{cm}^{2}$ was delivered to the top surface of the sample $(1200 \mathrm{~mW} /$ $\mathrm{cm}^{2} \times 10 \mathrm{sec}$ ). This was repeated for four further samples, giving five samples in total. Then, this was repeated for all combination of experimental groups.

To differentiate between the top and bottom surfaces, for later VH measurement, a black permanent mark was placed on the top surface of the ring using a permanent ink marker. 
The light energy delivered to the bottom surface of each sample was shown on the laptop software of MARC - RC. The light transmission (\%) was calculated as follows:

\section{Light transmission $(\%)=($ Bottom light energy/ Top light energy) $\mathbf{x} 100$}

The Mylar strips were removed and the cured samples were placed in their individual groups in clearly labelled light-proof paper envelopes, and the opening of the envelope stapled. All samples were stored in the envelopes in a dark at a room temperature of $\left(21+/-1^{0} \mathrm{C}\right)$ for 24 hours.

\section{Measurement of Vickers Microhardness}

The standard to reflect the adequate curing of RBCs using bottom to top surface $\mathrm{VH}$ ratio (\%) was set at $80 \%$ according to the literature [29].

After 24 hours storage post-irradiation, the VH was measured on both top and bottom surfaces of each sample using the Vickers Hardness tester (Figure 3). For each sample, the sample was placed on the tester platform and viewed under X50 magnification microscope (Figure 4). The magnified view was focused and the platform was moved in the horizontal plane to select a suitable area to make the indentation. The criteria for the selection of this were the smoothest surface possible, without microscopic voids, and close to the centre of the sample. Once located, the indentation button was pressed and the $\mathrm{VH}$ tester made the indentation with a previously configured 200g load applied for ten seconds.

When the indenter unloaded, the horizontal and vertical dimensions (D1 and D2) of the indentation were measured under microscopic vision, using the built-in measuring planes. This automatically gave the $\mathrm{VH}$ values directly on the LED screen as the tester automatically measures the depth of the indentation (D3). This method was repeated to take a total of three measurements close to the centre of the sample from the top surface and then repeated for the bottom surface three times.

For each sample, the data for top and bottom VH were entered into a Microsoft ${ }^{\oplus}$ Excel $^{\oplus}$ spreadsheet (Microsoft $^{\oplus}$ Office 2010, Microsoft ${ }^{\ominus}$ Corp., Redmond, WA,

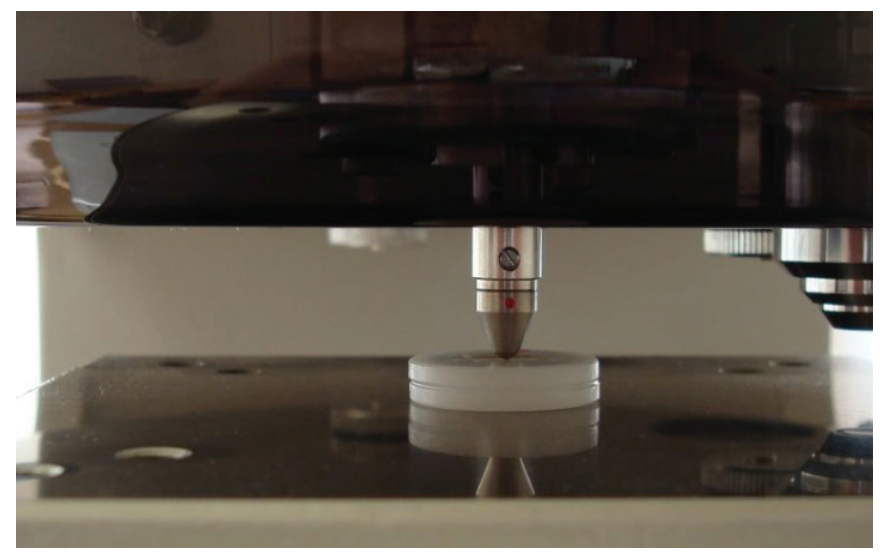

Fig. 3. VH indentation
USA), and the bottom to top $\mathrm{VH}$ ratio (\%) was calculated using the following formula:

\section{$\mathrm{VH}$ ratio $(\%)=$ mean bottom $\mathrm{VH}$ value /mean top $\mathrm{VH}$ value $\mathrm{x} 100$}

Using MARC ${ }^{\oplus} \mathrm{RC}$, the irradiance delivered to the top surface of the samples was adjusted to $1200 \mathrm{~mW} / \mathrm{cm}^{2}$ and delivered for 10 seconds $\left(12 \mathrm{~J} / \mathrm{cm}^{2}\right)$. The irradiance $(\mathrm{mW} /$ $\mathrm{cm}^{2}$ ) transmitted to the bottom surface was measured with MARC $^{\oplus}$ and the internal software converted this to $\mathrm{J} / \mathrm{cm}^{2}$. Three measurements were taken from both top and bottom surfaces of each sample using a Vickers Hardness Testing Machine (HM-200 Series, Mitutoyo Corporation, Tokyo, Japan) with $200 \mathrm{~g}$ load applied for 10 seconds. Bottom to top $(\mathrm{B} / \mathrm{T}) \mathrm{VH}$ ratios were calculated.

\section{Statistical Analyses}

Data were statistically analysed using one-way ANOVA $(\alpha=0.05)$.

The mean values of bottom light energy, light transmission (\%), and $\mathrm{VH}$ ratio (\%) in addition to the standard deviations (SD) for each group were calculated using Minitab $^{\circ} 16$ (Minitab Inc., State College, PA, USA). The dependent factors were bottom light energy, light transmission (\%), and $\mathrm{VH}$ ratio (\%). The independent factors were materials (4 levels), LCUs (2 levels) and total top light energy (1 level). The true power of the study was calculated using the same software. For each dependent factor, the greatest standard deviation of the means between groups was chosen to avoid over-estimating the power.

All statistical comparisons were conducted at the 95\% significant level of confidence intervals (CIs), and alpha value of 0.05 . If a confidence interval did not contain zero, there was a statistically significant difference between the corresponding means.

\section{Results}

The results are presented in Table III. There was no statistical significant difference for $\mathrm{B} / \mathrm{T}$ total energy transmission between materials except XF with Elipar ${ }^{\mathrm{TM}}$ S10 $(\mathrm{P}<0.001)$.

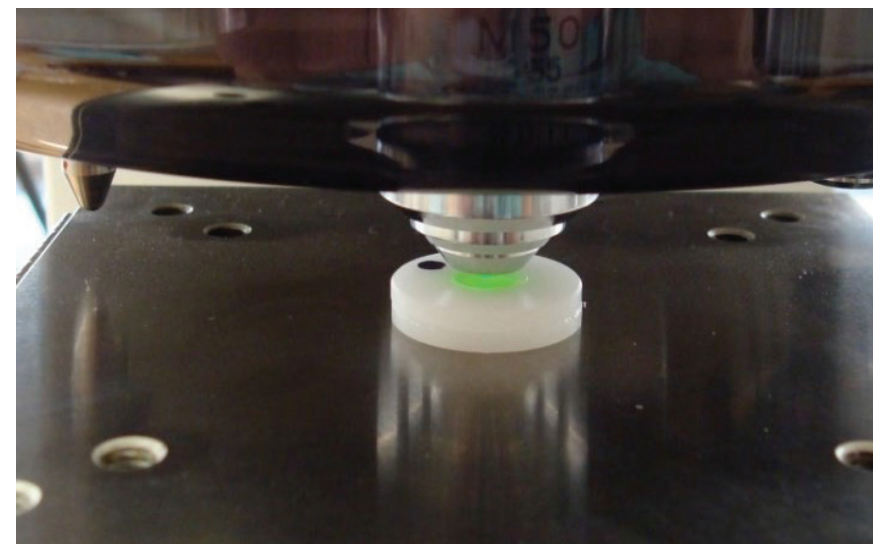

Fig. 4. VH magnification $\mathrm{X} 50$ 
The room temperature and humidity average readings were $21.0+/-1.0^{\circ} \mathrm{C}$ and $57.0 \%+/-5.0 \%$ respectively throughout the duration of the experimental phase of the study.

Total energy transmission ranged from $0.7 \mathrm{~J} / \mathrm{cm}^{2}$ (6.2\%) to $1.5 \mathrm{~J} / \mathrm{cm}^{2}$ (12.5\%). Between materials, $\mathrm{TEC}>\mathrm{SDR}>\mathrm{XF}>\mathrm{TBF}$. The mean of the total energy delivered to the bottom surfaces of all groups is presented in Table III and gives a broad view of the performance of each material.

There was no statistically significant difference for $\mathrm{B} / \mathrm{T}$ $\mathrm{VH}$ ratios (range, 63\% to 90\%) between materials ( $>>0.05)$ when materials were cured with single-peak versus dualpeak LCU's. Between materials, $\mathrm{XF}>\mathrm{SDR}>\mathrm{TEC}>\mathrm{TBF}$. TBF alone, did not reach the generally accepted $\mathrm{B} / \mathrm{T} \mathrm{VH}$ of $80 \%$.

The emission spectra of the LED LCUs used in this study measured with MARC- RC confirmed the single peak of Elipar ${ }^{\mathrm{TM}} \mathrm{S} 10$ and the dual peak nature of Bluephase G2 LED LCUs. While only the other peak, at $409 \mathrm{~nm}$, for the Bluephase ${ }^{\circ}$ G2 LED LCU overlapped the absorption spectrum of TPO, both units' emission spectrum coincided with the absorption spectrum of CQ (figure 5-8).

\section{Power Calculation}

This study had an $80 \%$ power to detect a difference of $0.3 \mathrm{~J} / \mathrm{cm}^{2}$ in bottom energy values, $2.3 \%$ in light energy transmission, and $10.7 \%$ in $\mathrm{VH}$ ratio.

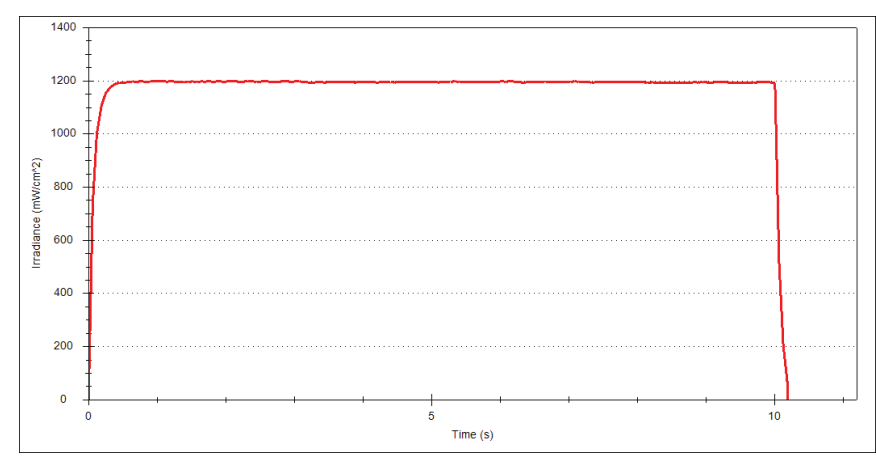

Fig. 5. Graph produced during calibration of EliparTM S10 at 1200 $\mathrm{mW} / \mathrm{cm} 2$

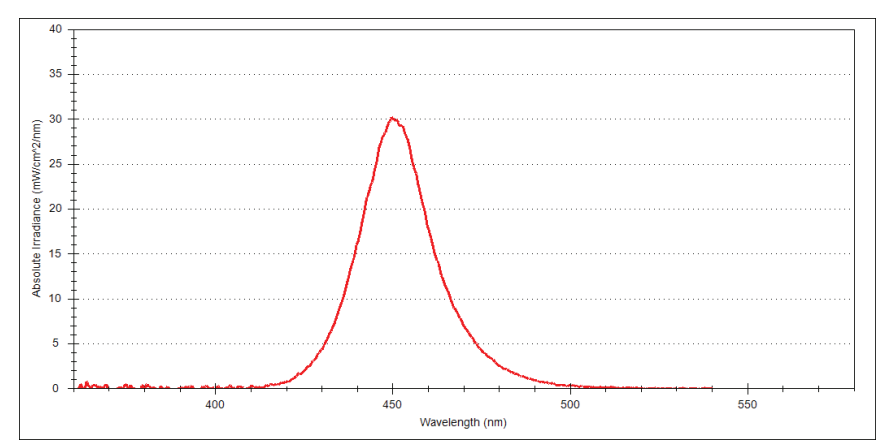

Fig. 6. Emission spectrum - EliparTM S10 


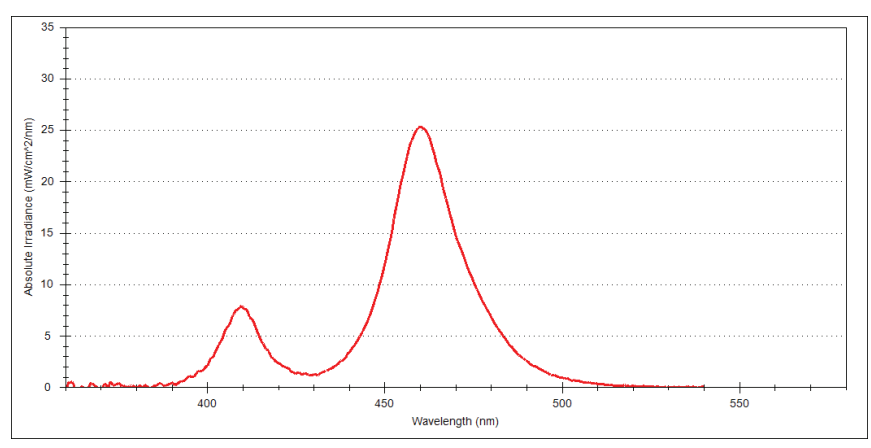

Fig. 7. Emission spectrum - Bluephase ${ }^{\circledR} \mathrm{G} 2$
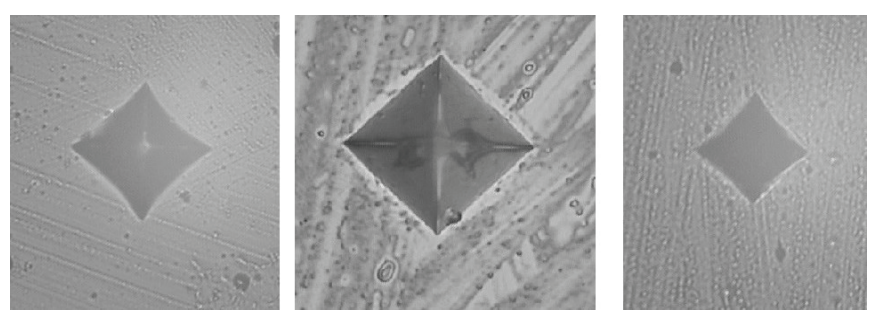

Fig. 8. Examples of VH indentations under X50 magnification

\section{Discussion}

\section{Selection of materials}

At the time of conducting this study, there were only ten brands of bulk-fill materials on the market worldwide. Five of them were viscous and five flowable. In this study, two viscous and one flowable bulk-fill materials were used from well-known manufacturers. These were felt to be representative of the two classes of RBC consistency.

The selection for the control composite, Tetric EvoCeram $^{\oplus}$, was made because it was sold by Ivoclar Vivadent, the same manufacturer producing the bulk-fill material, Tetric EvoCeram ${ }^{\oplus}$ Bulk Fill, and the dual peak LED LCU (Bluephase ${ }^{\bullet}$ G2), both of which were used in this study.

Consideration of the effect of shade of the RBCs was important since this may influence the results. There were different shade classifications between manufacturers and some materials were only available in one shade, a Universal shade. An effort was made to match the study shade to A2 whenever an appropriate material was available from the manufacturer to avoid extra-white or extra-dark shades and also because this was probably the most commonly used in clinical dental practice.

\section{Selection of LCUs}

Previous workers in their studies on BFMs used mainly a single peak LED LCU $[23,26,27]$ or QTH [ 28]. Furthermore, most of the RBC manufacturers specify the irradiance and time required to cure their materials without specifying the type of LCU or the spectral wavelength to ensure compatibility. It is important that clinicians are made aware of the constituents of RBCs, especially the type of photo-initiator, so that a compatible light source can be used [30]. Unfortunately, some manufacturers of these RBCs do not specify these details.

As the stated aim of this study was to investigate the effect of single peak and dual peak LED LCUs on curing bulk-fill materials, it was decided to compare one single peak (Elipar ${ }^{\mathrm{TM}}$ S10) with one dual peak LED LCU (Bluephase ${ }^{\otimes}$ G2). Selection of the latter was made because it was sold by Ivoclar Vivadent, the same manufacturer producing the bulk-fill material, Tetric EvoCeram ${ }^{\circledR}$ Bulk Fill, and the conventional control RBC, Tetric EvoCer$\mathrm{am}^{\circ}$, both of which were used in this study. Elipar ${ }^{\mathrm{TM}} \mathrm{S} 10$ was selected from another company (3M ESPE) because it was well-known and had been used in several earlier studies [26].

\section{Selection of Measuring Instruments}

The use of MARC $^{-}-\mathrm{RC}$ in this experiment provided an objective and reasonably straightforward method to standardise the LCU irradiance on the top surface and to measure the light transmission through the samples to the bottom surface. The availability of MARC $-\mathrm{RC}$ for this study proved to be advantageous because measurements of the emission spectrum, irradiance, energy distribution and the total energy were easily obtained in a short period of time. Although, it would be optimum to measure DC directly to give a more direct result about a material's polymerization, the $\mathrm{VH}$ tester was easy to use and provided a means of indirect evaluating the degree of cure. Considering our lack of availability of devices like FTIR and micro-Raman, and reported good correlation between $\mathrm{VH}$ and DC, the $\mathrm{VH}$ tester was used in this study.

\section{Selection of Total Energy value delivered to the top of the specimen}

An important aspect, often ignored in previous studies, is where the light tip of the curing unit is placed in relation to the top surface of the material. When placed directly against the material, higher levels of energy would be delivered to top, and possible subsequently to the bottom surface. Alshali et al. [28] delivered a lower total energy to the top surface than was recommended by the manufacturers, placing the LCU at a distance from the surface. This would result in less total energy delivered to top surface which in turn may affect the curing of the material; thus not appropriate to judge the material as failed to be adequately cured.

In this study, the materials used varied in the total energy recommended by the manufacturers for curing their materials. The total energy recommended by the manufacturers of Tetric EvoCeram ${ }^{\odot}$ Bulk Fill, X-tra fil ${ }^{\oplus}$, SureFil SDR ${ }^{\mathrm{TM}}$ and the control material, Tetric EvoCeram $^{\odot}$ ranged between 8 and $12 \mathrm{~J} / \mathrm{cm}^{2}$. Thus $12 \mathrm{~J} / \mathrm{cm}^{2}$ should have been more than sufficient to achieve adequate polymerization of the materials. 


\section{Calibration and Standardisation of LCUs}

Prior to LCU calibration, a Mylar strip was placed over the top sensor. This was performed because the Mylar strip will be used on top and bottom surface of the samples, and thus, standardising the possible effect of its placement on the light scattering or absorption.

LCU calibration was repeated between experimental groups to ensure standardisation and not between each irradiation because it was not thought likely that significant deterioration of the LCUs through short continuous use would be expected.

\section{Sample Thickness}

A sample thickness of $4 \mathrm{~mm}$ was used in this study both because it was recommended by the manufacturers of the materials and to assess the non- incremental packing technique, the bulk packing technique. This was compared to $2 \mathrm{~mm}$ thick samples of the conventional composite which provided the standard.

Mylar strips were used by most of the earlier studies. However, Bucuta \& Ilie [27] used a thin transparent plastic foil instead of the Mylar strip, because it demonstrated less light absorption in their primary tests than Mylar strip. The aims of using Mylar strips during sample preparation were to produce a flat and smooth surface and to minimise the formation of the oxygen-inhibition layer. However, this layer is not completely preventable during sample preparation and is unavoidable clinically. In this study, Mylar strips were used to make smooth surface for the ease of indentation measurement and to avoid the need for polishing. This was confirmed during the training on VH tester. Polishing of the sample surfaces has been done in several of the earlier studies [23,27]. However, in this study, the surfaces were not polished prior to testing. This was for several reasons. In the earlier studies, the aims of polishing were to produce a smooth surface and to remove the oxygen- inhibition layer. The latter has been shown to affect the reading of FTIR and micro- Raman when measuring the DC. As to the effect of polishing on $\mathrm{VH}$ measurements, it was reported that polishing sample surface will result in a higher $\mathrm{VH}$ value [31]. Conversely, Chung and Yap [32] concluded that surface hardness was independent of the surface finish provided because the indenter penetration was sufficiently deep. In addition, in this study, the bottom to top surface $\mathrm{VH}$ ratio (\%) was recorded and not each surface value in isolation, thus this should not affect the ratio as neither surface was polished [31]. Polishing of the composite surfaces is not clinically relevant and does not simulate the clinical situation especially when polishing the bottom surface. Furthermore, when the surfaces were polished as a part of the $\mathrm{VH}$ test training, polishing resulted in a less clear surface when viewed under magnification as a result of dust creation. Therefore polishing was not carried out. Polishing also may result in heat generation that may affect polymerization [31]. Also, the use of Mylar strips in this study resulted in smooth and clear surfaces for the ease of $\mathrm{VH}$ indentation, which eliminated the need for surface polishing.

\section{Sample Storage}

In similarity to several earlier studies, in this study, after curing, the samples were stored for 24 hours in lightproof paper envelopes in the dark, thus allowing the dark phase of polymerization to take place. However, studies have varied in the use of a storage medium. Some studies stored their samples dry [26] while other stored them wet in distilled water $[23,25,27]$. In common, all of these studies kept the temperature at $37^{\circ} \mathrm{C}$ in an attempt to simulate the intra-oral condition. In contrast to this study, the samples were stored dry at room temperature. Given this was laboratory study, dry storage at room temperature was felt to be sufficient considering the standardisation methods used for all samples.

MARC ${ }^{\circledR}$ RC and Measuring Light Transmission: Transmission measurements are the essential starting point to all other property testing of RBCs [33] thus the light transmission measurements, when combined with the $\mathrm{VH}$ ratio (\%), would be beneficial and advantageous to this study. Prior to the calibration of the LCU in this study, a clear Mylar strip was placed in contact over the top sensor. This was performed because the Mylar strip was to be used on the top and bottom of the samples, thus, standardising the total energy delivered to the top surface of samples. Through the calibration process and measuring of the bottom light energy, it was shown that MARC ${ }^{\circledR}$-RC had a good reproducibility, with the possible confounding factor of variety between manual sample preparations.

\section{VH Indentation}

In this study, the VH indentations were made using a 200 $\mathrm{g}$ load for ten seconds. The selection of these experimental conditions was based on the outcomes of many trials during training on the $\mathrm{VH}$ tester. The indentation should give the same $\mathrm{VH}$ value regardless of the load and duration used as the principle is measuring three- dimension indentation. It is all about how clear and easy to measure the indentation. If too small, it is likely to be hard to measure, or too big, the borders of the indentation may be out of focus.

The mean bottom light energy in the present investigation ranged from 0.7 to $1.5 \mathrm{~J} / \mathrm{cm}^{2}$, the light transmission (\%) ranged from 6.2 to $12.5 \%$ and $\mathrm{VH}$ ratio (\%) ranged from 63 to $90 \%$. It is not always appropriate to compare the value reached in this study with previous works because the top energy delivered in the studies varied. Compared to the $12 \mathrm{~J} / \mathrm{cm}^{2}$ delivered in this study, Alshali et al. (2013) for example, delivered only $12 \mathrm{~J} /$ $\mathrm{cm}^{2}$ to all samples despite some of the materials having higher energies recommended by their manufacturers. In contrast, Bucuta \& Ilie [27] delivered $34.6 \mathrm{~J} / \mathrm{cm}^{2}$ top energy for all materials which was much higher than recom- 
mended. It could be speculated that this difference arose because of variations in the distance between the LCU tip and the material surface factor considered in these studies for the LCU to be at $0 \mathrm{~mm}$ tip to top surface distance or at specific distance. Placing the tip of LCU in contact with the top surface of the restoration cannot be achieved clinically because of the tooth cusps, and hence the distance factor was not investigated in this study.

For this study, the standard selected to reflect the adequate curing of $\mathrm{RBC}$ using the bottom to top surface $\mathrm{VH}$ ratio (\%) was $80 \%$ [26]. This was in agreement with all studies measuring $\mathrm{VH}$ ratio (\%). In this study, with a $\mathrm{VH}$ ratio (\%) of less than $80 \%$, Tetric EvoCeram ${ }^{\circledR}$ Bulk Fill was not sufficiently cured in $4 \mathrm{~mm}$ thick increments when the manufacturers' recommendations were followed. This emphasized the care needed when following the manufacturers' instructions and the importance of carrying out such independent studies.

The findings of this study were in contrast to the results obtained by Bucuta \& Ilie [2 7] and Alrahlah [26] when all BFMs used in their studies reached a $\mathrm{VH}$ ratio of $80 \%$ at $4 \mathrm{~mm}$ thickness. This might be explained by the fact that Bucuta and Ilie [26] used the LCU for 20 seconds in contact with the top surface of the samples (distance 0 $\mathrm{mm}$ ) delivering $34.6 \mathrm{~J} / \mathrm{cm}^{2}$ top energy, and Alrahlah [26] used the LCU with an intensity of $1200 \mathrm{~mW} / \mathrm{cm}^{2}$ for 20 sec, delivering $24 \mathrm{~J} / \mathrm{cm}^{2}$ top energy, both of which were much higher than the manufacturers' recommendation.

The influence of the type of LCU used on the bottom energy values and light transmission was different from o n e material to another. The $\mathrm{H} 0(1)=0$ was accepted for Tetric EvoCeram ${ }^{\bullet}$ Bulk Fill, SureFil SDR ${ }^{\mathrm{TM}}$ and the conventional composite Tetric EvoCeram ${ }^{\bullet}$ where there was no significant difference in the bottom energy and light transmission (\%) between the Elipar ${ }^{\mathrm{TM}} \mathrm{S} 10$ and the Bluephase ${ }^{\oplus}$ G2 LCUs. In contrast, the bottom energy and light transmission (\%) of X-tra fil ${ }^{\circ}$ when cured with the Elipar ${ }^{\mathrm{TM}}$ S10 were significantly greater than when cured with the Bluephase G2 LCUs. Therefore H0 (1) was partially rejected.

The influence of the type of LCU used on the VH ratio (\%) was not significantly different for a 11 materials when cured with the Elipar ${ }^{\mathrm{TM}}$ S10 compared to the Bluephase $^{\bullet}$ G2. Therefore, $\mathrm{H}_{0}$ (2) was accepted.

The shade and opacity, and filler particle size and distribution can affect the transmission of light through a material $[30,34,35]$. and therefore the degree of cure $[34,36,37]$. The presence of unknown photo-initiators can also influence these results. In this study, the manufacturers failed to accurately state the photo- initiators contained in their materials and therefore it was assumed that the majority contain CQ [27].

As some materials also showed better $\mathrm{VH}$ ratio (\%) at lower light energy transmission (\%), it needs to be emphasized that the polymerization process in the bottom surface is not only dependent on the volume of light/pho- tons reaching this surface but also from the polymerization process already initiated in the upper layers. The results of better $\mathrm{VH}$ ratio (\%) at lower light energy transmission were in agreement with the results obtained by Bucuta $\&$ Ilie [27].

One advantage of this study, over other studies, was to include the control material, Tetric EvoCeram. This gave an over view of the BFMs compared to a conventional composite cured in a $2 \mathrm{~mm}$ thick increment.

In this study, the control material, Tetric EvoCeram ${ }^{\oplus}$, when cured in a $2 \mathrm{~mm}$ thick increment, recorded a bottom energy of $1.5 \mathrm{~J} / \mathrm{cm}^{2}, 1.3 \mathrm{~J} / \mathrm{cm}^{2}$, a light transmission (\%) of $12.5 \%, 11.2 \%$ and a $\mathrm{VH}$ ratio (\%) of $80.7 \%$, $78.9 \%$, when cured with Elipar ${ }^{\mathrm{TM}} \mathrm{S} 10$ and the Bluephase G2 LCUs, respectively.

\section{Power of the Study}

The power calculation based on the results of this study indicated that the difference detected at this power would be $0.3 \mathrm{~J} / \mathrm{cm}^{2}$ in bottom energy values, $2.3 \%$ in light energy transmission, and $10.7 \%$ in $\mathrm{VH}$ ratios. The greatest standard deviation of the means between the groups was chosen to avoid over-estimating the power. Therefore, the source of disparity in the detected difference may be related to the greater variance in these groups. Other groups in this study had SD ranges from 0.1 to 5.3 and therefore using a lower SD would result in lower deference detection. This could be reduced in future work by increasing the sample size especially if the materials with a higher SD are used.

\section{Conclusions}

The RBC materials all showed different results when compared to each other.

Two of the BFMs did not reach a VH ratio of $80 \%$ when cured according to manufacturer's instructions.

Some materials will benefit from increasing curing time, a recommendation of 20 seconds curing over 10 seconds.

Both single peak and dual peak LCU's were equally effective for curing the studied bulk fill materials.

Manufacture's recommended total energy delivered to the top surface may not always be sufficient for effective curing.

It is important that manufacturers accurately identify the photoinitiators used in their materials, to ensure that a LCU with an appropriate emission spectrum is used.

\section{References}

1. Aldossary $M$ \& Santini $A$. Resin-Based Composite and LCU-related Factors affecting the Degree of Cure. A Literature Review: Part 1. Resin-Based Composites. Acta Medica Marisiensis 2015[accepted for publication]

2. Aldossary M \& Santini A. Resin-Based Composite and LCU-related Factors affecting the Degree of Cure. A Literature Review: Part 2. Light Curing Units \& Related Factors Affecting the Degree of Cure. Acta Medica Marisiensis 2015[accepted for publication]

3. Bowen RL, Rodriguez MS. Tensile strength and modulus of elasticity 
of tooth structure and several restorative materials. J Am Dent Assoc 1962;64:378-387.

4. Bassiouny MA.\& Grant AA. A visible light-cured composite restorative. Clinical open assessment. Br Dent J. 1978;145:327-30.

5. Santini A. Current status of visible light activation units and the curing of light-activated resin-based composite materials. Dent Update. 2010;37:214-6,218-20,223-7.

6. Ferracane JL. Resin composite-state of the art. Dent Mater. 2011;27:29-38.

7. Peutzfeldt A.\& Asmussen E. Resin Composite Properties and Energy Density of Light Cure. Journal of Dental Research. 2005;84:659-662.

8. Leprince JG., Hadis M., Shortall AC, et al. Photoinitiator type and applicability of exposure reciprocity law in filled and unfilled photoactive resins. Dent Mater. 2011;27:157-64.

9. Hadis MA., Shortall AC. \& Palin WM. Specimen aspect ratio and light transmission in photoactive dental resins. Dent Mater. 2012;28:1154-61.

10. Feilzer AJ., De gee AJ.\& Davidson CL. Setting stress in composite resin in relation to configuration of the restoration. J Dent Res. 1987;66:1636-9.

11. Caughman WF., Rueggeberg FA.\& Curtis JW. JR. Clinical guidelines for photocuring restorative resins. J Am Dent Assoc. 1995;126:1280$2,1284,1286$.

12. Price RB., Derand T., Loney RW.\& Andreou P. Effect of light source and specimen thickness on the surface hardness of resin composite. Am J Dent 2002;15:47-53.

13. Pilo R., Oelgiesser D.\& Cardash HS. A survey of output intensity and potential for depth of cure among light-curing units in clinical use. J Dent. 1999;27:235-41.

14. Koupis NS., Martens LC.\& Verbeeck RM. Relative curing degree of polyacid-modified and conventional resin composites determined by surface Knoop hardness. Dent Mater. 2006;22:1045-50.

15. Flury S., Hayoz S., Peutzfeldt A., Husler J. \& Lussi A. Depth of cure of resin composites: is the ISO 4049 method suitable for bulk fill materials? Dent Mater. 2012;28:521-8.

16. Abbas G., Fleming GJ., Harrington E., Shortall AC.\& Burke FJ. Cuspal movement and microleakage in premolar teeth restored with a packable composite cured in bulk or in increments. J Dent. 2003;31:437-44.

17. Burgess J.\& Cakir D. Comparative properties of low-shrinkage composite resins. Compend Contin Educ Dent. 2010;31(2):10-5.

18. llie N.\& Hickel R. Investigations on a methacrylate-based flowable composite based on the SDR technology. Dent Mater 2011;27:348-55.

19. Jun SK., Kim DA., Goo HJ.\& Lee HH. Investigation of the correlation between the different mechanical properties of resin composites. Dent Mater J. 2013;32:48-57.

20. Christensen GJ. Advantages and Challenges of Bulk-Fill Resins. Clinicians Report. 2012;5:1-2.

21. El-safty S, Silikas N.\& Watts DC.. Creep deformation of restorative resincomposites intended for bulk-fill placement. Dent Mater 2012;28:928-35.
22. Finan L., Palin WM., Moskwa N., McGinley EL.\& Fleming GJ. The influence of irradiation potential on the degree of conversion and mechanical properties of two bulk-fill flowable RBC base materials. Dent Mater, 2013;29(8):906-912.

23. Ilie N., Kessler A.\& Durner J. Influence of various irradiation processes on the mechanical properties and polymerization kinetics of bulk- fill resin based composites. J Dent. 2013;41:695-702.

24. Campodonico CE., Tantbirojn D., Olin PS.\& Versluis A. Cuspal deflection and depth of cure in resin-based composite restorations filled by using bulk, incremental and transtooth-illumination techniques. J Am Dent Assoc, 2011;142: 1176-82.

25. Czasch P.\& llie N. In vitro comparison of mechanical properties and degree of cure of bulk fill composites. Clin Oral Investig. 2013;17:227-35.

26. Alrahlah A., Sllikas N. \& Watts DC. Post-cure depth of cure of bulk fill dental resin-composites. Dent Mater, 2014;30:149-54.

27. Bucuta S.\& llie N. Light transmittance and micro-mechanical properties of bulk fill vs. conventional resin based composites. Clin Oral Investig, 2014;1-10.

28. Alshali RZ., Silikas N.\& Satterthwaite JD. Degree of conversion of bulk-fill compared to conventional resin-composites at two time intervals. Dent Mater 2013;29:e213-7.

29. Bouschlicher MR., Rueggeberg FA.\& Wilson BM. Correlation of bottomto-top surface microhardness and conversion ratios for a ariety of resin composite compositions. Oper Dent 2004;29:698-704.

30. Alvim HH., Alecio AC., Vasconcellos WA., et al. Analysis of camphorquinone in composite resins as a function of shade. Dent Mater 2007;23: 1245-9.

31. Chinelatti MA., Chimello DT., Ramos RP.\& Palma-Dibb RG.. Evaluation of the surface hardness of composite resins before and after polishing at different times. J Appl Oral Sci 2006;14:188-92.

32. Chung SM, Yap AU. Effects of surface finish on indentation modulus and hardness of dental composite restoratives. Dent Mater. 2005;21:1008-16.

33. Price RB.\& Felix CA. Effect of delivering light in specific narrow bandwidths from 394 to $515 \mathrm{~nm}$ on the micro-hardness of resin composites. Dent Mater. 2009;25:899-908.

34. Thome T., Steagall W. JR., Tachibana A., Braga SR.\& Turbino ML. Influence of the distance of the curing light source and composite shade on hardness of two composites. J Appl Oral Sci. 2007;15:486-91.

35. Guiraldo RD., Consani S., Consani RL., et al. Light energy transmission through composite influenced by material shades. Bull Tokyo Dent Coll. 2009;50:183-90.

36. Shortall AC. How light source and product shade influence cure depth for a contemporary composite. J Oral Rehabil. 2005;32:906-11.

37. Jeong TS., Kang HS., Kim SK., et al. The effect of resin shades on microhardness, polymerization shrinkage, and color change of dental composite resins. Dent Mater J. 2009;28:438-45. 